\title{
ENSINO DE LÍNGUAS ESTRANGEIRAS EM PROJETOS DE EXTENSÃO: AMPLIANDO CONCEPÇÕES DE LINGUAGEM E FORTALECENDO O COMPROMISSO SOCIAL DO PROFESSOR
}

\author{
Jonathan FERREIRA \\ Universidade Federal da Paraíba \\ Jéssica BATISTA \\ Universidade Federal da Paraíba
}

RESUMO: Esse trabalho descreve as experiências vivenciadas por dois bolsistas de extensão nos projetos de extensão Inglês para Adolescentes e Jovens: uma ferramenta para profissionalização e o letramento critico, e Língua e cultura francesa para a comunidade acadêmica e externa, ambos implementados na Universidade Federal da Paraíba. O primeiro projeto, envolvendo a língua inglesa, ofereceu aulas de inglês para jovens de condições socioeconômicas desfavorecidas em uma instituição não governamental de João Pessoa. $\mathrm{O}$ segundo projeto, na área de língua francesa, teve como objetivo o ensino de língua e cultura francesas através de diversos gêneros textuais a adultos e pessoas da terceira idade que integram a comunidade universitária e externa da UFPB. Procura-se avaliar os saberes construídos pelos bolsistas ao longo dos projetos (TARDIF, LESSARD, 2011) e se discute como os desafios encontrados foram importantes para ampliação dos conhecimentos dos professores em formação inicial. Quanto à metodologia de pesquisa, foram examinados de forma interpretativa os relatórios finais dos bolsistas, planos de aula e relatos reflexivos buscando-se identificar os aspectos positivos para a formação, mas também as dificuldades encontradas na ministração das aulas, e que estratégias foram utilizadas pelos bolsistas para lidar com essas situações adversas. No que diz respeito aos benefícios para a formação docente dos participantes, a pesquisa sugere que a participação em projetos voltados para atender os interesses de diferentes públicos tem facilitado o desenvolvimento de uma atitude participativa, cidadã e comprometida com o desenvolvimento e a justiça social por parte dos professores em formação (BRASIL, 2015), como também tem possibilitado a construção de saberes (pedagógicos e no campo das linguagens) sensíveis às necessidades e às demandas dos alunos das faixas etárias, níveis socioeconômicos e contextos atendidos.

PALAVRAS-CHAVE: Ensino de língua estrangeira; Extensão; Formação inicial de professores

ABSTRACT: This article describes the experience of two undergraduate students involved with the extension projects English for youths and teenagers: a tool for professionalization and critical literacy, and Language and French culture to the academic and extramural community, both implemented by the Federal University of Paraíba. The first one, involving the English language, offered English lessons to unfavoured youth in a non-governmental organization in João Pessoa - PB. The second one, involving the French language, aimed at teaching the French language and culture through several textual genres to adults and to elderly people from the UFPB academic community and from the neighbouring areas. The research is intended to assess what kind of professional learning took place, considering the teachers-to-be involved in these projects and to discuss how the challenges along the course helped the teachers in initial training to expand their knowledge. As far as the methodology is concerned, the teacher's final reports on the project were examined, as well as lesson plans and reflexive journals in an interpretative approach, in search of finding positive aspects to their teacher development, the challenges faced while teaching and what strategies were used to deal with the adverse 
scenarios. Concerning the benefits for the participants in their teacher development, the research suggests that participating in projects which focus on attending the different interests of a diverse public assists the teachers-to-be to develop an engaged, citizen-like attitude, committed to the development and social justice (BRASIL, 2015). It also allows the construction of knowledge (pedagogical and in the field of linguistics) sensible to the needs and demands of the public assisted.

KEYWORDS: Foreign language teaching; Extension; Teacher development

RÉSUMÉ: Ce travail décrit les expériences vécues par deux étudiants boursiers de l'extension dans les projets d'extension Anglais pour adolescentes et jeunes: um outil pour la professionnalisation et l'alphabétisation conscientisante et Langue et culture française pour la communauté academique et extérieure, tous deux realisés à l'Universidade Federal da Paraíba. Le premier projet, concernant la langue anglaise a offert des cours d'anglais pour des jeunes d'un milieu socio-économique défavorisé dans une institution non gouvernementale de João Pessoa. Le second projet dans le domaine de langue française a eu comme objectif l'enseignement de langue et culture françaises à travers les divers genres textuels à des adultes et personnes agées qui font partie de la communauté universitaire et extérieure de l'UFPB. On cherche évaluer les savoirs construits par les boursiers au long des projets (TARDIF, LESSARD, 2011) et on discute comme les défis rencontrés ont été importants pour l'accroissement des connaissances des enseignants en formation initiale. Quant à la méthode de recherche ont été examinés de façon interprétative les rapports finaux des boursiers, en cherchant à identifier les aspects positifs pour la formation, mais aussi les dificultés rencontrées dans la pratique d'enseignement, et quelles stratégies ont été utilisées par les enseignants en formation pour faire face à ces situations difficiles. Dans ce qui concerne les avantages pour la formation des participants, cette recherche suggère que la participation dans des projets pour tenir compte des intérêts des différents publics a facilité le développement d'une attitude participative, citoyenne et engagée avec le développement et la justice sociale de la part des enseignants en formation (BRASIL, 2015) comme a permis aussi la construction de savoirs (pédagogiques et dans le domaine des langages) sensibles aux besoins et aux demandes des élèves des classes d'âge, des niveaux sócio-économiques et des contextes servis.

MOTS-CLÉS: Enseignement de langue étrangère; Extension; Formation initiale des enseignants

\section{Introdução}

Os primeiros passos na profissão docente de alunos dos cursos de Letras Estrangeiras modernas são marcados por incertezas e questionamentos sobre os ônus e bônus de ser professor. Sabe-se também que muitos deles apenas terão contato com a sala de aula e o gênero profissional docente (CLOT, 2009) nos últimos semestres de sua graduação, uma vez inseridos no sistema educacional tradicional da maior parte das universidades, que, por sua vez, privilegia uma formação com caráter conteudista em detrimento daquela pautada pela experiência e o aprendizado acerca dos aspectos didáticos de ensino. (SAVIANI, 2009 apud GUEDES-PINTO, 2016). Como solucionar o impasse entre uma formação excludente em termos de forma e conteúdo, bem como responder às dúvidas de discentes matriculados em um curso cujo objetivo principal tem sido formar professores que atuarão nas escolas de ensino fundamental e médio, mas que esperarão até o último ano para exercerem minimamente a profissional através dos estágios supervisionados? 
Nesta conjuntura, situam-se os projetos de extensão fomentados pelas universidades em geral e também pela Universidade Federal da Paraíba, os quais tem como meta promover a produção e democratização do saber, o desenvolvimento e a organização da sociedade, a formação de cidadãos conscientes de seus direitos e das responsabilidades do exercício da cidadania. Ora, se o impasse supracitado enfatiza a falta de prática dos professores em sua formação inicial, a qual, pode ampliar as concepções de linguagem aprendidas em sala de aula, além de propiciá-los as experiências necessárias sobre as nuances do ser professor, não poderia a atividade de extensão ser uma das chaves para abertura das portas do "saber fazer" para os alunos tenros?

Destarte, este artigo busca responder os questionamentos dos estudantes dos cursos de letras estrangeiras modernas quanto ao gênero profissional docente, ampliar as concepções de linguagem emergentes e fortalecer o compromisso social do professor. Para tanto, analisaremos os relatos de experiência de dois bolsistas alunos de Letras, habilitações Inglês e Francês, da Universidade Federal da Paraíba em sua formação inicial e vinculados aos projetos de extensão Adolescentes e Jovens: uma ferramenta para a profissionalização e o letramento crítico, e Língua e cultura francesa para a comunidade acadêmica e externa.

Com as análises, evidenciaremos aspectos teóricos que permeiam a formação inicial destes estudantes em seus relatos reflexivos e planos de aulas, bem como os saberes construídos ao longo de suas atuações nos projetos de extensão, enfatizando seus aprendizados e dificuldades com o gênero profissional.

Em relação a metodologia aplicada para esta análise dos dados coletados dos planos de aula, diários reflexivos e relatório final, apoiamo-nos em uma análise interpretativa (AUTOR E ANO), a partir da qual analisaremos trechos dos instrumentos acima mencionados e relacionaremos aos aspectos teóricos aprendidos com a experiência em ambos os projetos de extensão, bem como as evidências das dificuldades encontradas e as ferramentas e meios utilizados para superá-las.

\section{Os contextos:}

\subsection{PROBEX Letras inglês}

Este trabalho foi desenvolvido ao longo de 2015, ano este situado entre dois eventos internacionais acontecendo em solo brasileiro, a Copa do Mundo de futebol em 2014 e as Olimpíadas já em 2016. Sendo assim, acreditávamos que a demanda por profissionais aptos a trabalhar com o público estrangeiro visitante, ou seja, prováveis falantes da língua inglesa, seria bem maior em todos os contextos, em especial, os de turismo e hotelaria. Também cientes dessa demanda, organizações não-governamentais (doravante ONGs) incluíram em suas agendas educacionais cursos de inglês para viabilizar a qualificação dos jovens participantes dos projetos das instituições. Por outro lado, ao mesmo tempo em que essas ONGs, muitas vezes situadas em espaços marginalizados e carentes, buscam proporcionar oportunidades profissionais, há uma preocupação em formar sujeitos capazes de entender os sentidos que circulam ao seu redor de forma crítica e conscientes de seus direitos e deveres enquanto cidadãos.

Destarte, o projeto de extensão Inglês para Adolescentes e Jovens: uma ferramenta para profissionalização e o letramento crítico vinculado a Universidade Federal da Paraíba, ${ }^{1}$,

\footnotetext{
${ }^{1}$ Curso coordenado pela Profa. Dra. Angélica Araújo de Melo Maia
} 
visou capacitar jovens e adolescentes advindos do ensino público a atuarem nos setores hoteleiro e alimentício, instrumentalizando-os a se comunicar pontual e minimamente com os turistas visitantes destes eventos globais. Não obstante, conscientes da função social da língua, objetivamos ajudar os jovens a construir sentidos sobre sua realidade a partir da leitura de pequenos textos relacionados a temas abrangentes da esfera social, os quais não apenas desenvolvessem suas habilidades interpretativas, mas também motivassem o debate e um posicionamento crítico.

Para tanto, tivemos o apoio da ONG Casa Pequeno Davi, situada em uma comunidade carente na cidade de João Pessoa-PB, que tem como missão "contribuir para efetivação dos Direitos Humanos, em especial de Crianças e Adolescentes em situação de vulnerabilidade social, com ações de educação integral, articulação comunitária e institucional e intervenção nos espaços de políticas públicas da Paraíba, numa perspectiva de desenvolvimento sustentável" (www.pequenodavi.org.br).

O público-alvo consistiu de um grupo em situação de vulnerabilidade social e/ou pessoal, uma vez que, em sua totalidade, $82 \%$ considerava-se parda/os e negra/os, e aproximadamente 20\% definia-se homossexual. Deste público, uma média de 15 alunos entre 16 e 24 anos participantes de projetos oferecidos pela ONG e moradores da comunidade onde ela se situa frequentaram 32 horas de aula, divididas em 2 séries de 8 encontros semanais com duas horas de duração. Aqui, ressaltamos a articulação do projeto de extensão em questão com outro disponibilizado pela Casa Pequeno Davi, intitulado "Exploração sexual de adolescentes e jovens: faça um gol contra". Sua principal meta era a profissionalização de jovens e adolescentes da comunidade como medida preventiva e combate à exploração sexual, que foi um dos temas trabalhados nas oficinas de língua inglesa.

\subsection{PROBEX: Letras-Francês}

Sabemos que a aprendizagem de uma língua estrangeira permite ao indivíduo inserir-se em uma nova cultura e ampliar o seu conhecimento de mundo. Além de um instrumento de expressão e comunicação, é a via que conduz o falante a uma experiência de trocas culturais A língua francesa é uma das línguas mais faladas no mundo, e assim como a língua inglesa, é falada nos 5 continentes, sendo uma língua oficial e de trabalho de grandes instituições internacionais, tais como a ONU, União Europeia e o Comitê Olímpico Internacional.

Neste contexto, o projeto de extensão* "Língua e cultura francesa para a comunidade acadêmica e externa" desenvolvido no ano de 2015 consistiu na ministração de aulas presenciais, uma vez por semana, com duração de 2 horas, para alunos e funcionários adultos e de terceira idade da UFPB e da comunidade externa, levando em consideração a política de extensão da Instituição. As aulas se deram em uma turma de nível iniciante A1 que contou com cerca de 20 alunos.

Em relação à cultura na sala de aula, foram abordados, através de gêneros textuais, diversos temas socioculturais como a gastronomia francesa, festas tradicionais, música e cantigas de roda. Além disso, tivemos uma aula com nativos, 3 estudantes de Lyon (França) que prepararam uma aula apresentando um pouco da cultura francesa e, mais especificamente, de sua cidade. Os alunos adoraram a experiência e se mostraram muito entusiasmados, pois puderam se comunicar pela primeira vez com nativos, colocando em prática o conteúdo que

\footnotetext{
* Coordenado pela professora Dra. Sandra Helena Gurgel Dantas de Medeiros (PROBEX - UFPB)
} 
estudaram e também fazendo trocas culturais, através de análises contrastivas de seus costumes com os dos franceses e observando os accents (sotaques) diferentes.

Deste modo, o projeto em questão possibilitou que os alunos entrassem em contato com os aspectos socioculturais e interculturais e, segundo Chianca (2006), "no momento em que os alunos descobrem uma língua estrangeira, a interação entre esta e sua própria cultura leva a uma redefinição de identidade materna e ao reconhecimento das diferenças. É, portanto, através dos procedimentos de relação entre a cultura de origem e a cultura alvo que uma reflexão sobre a identidade pode estabelecer-se na aula de língua. ”. As OCEM (BRASIL, 2006) ressaltam justamente que o ensino da língua estrangeira e materna deve contemplar não somente os aspectos linguísticos, mas também estabelecer uma relação entre estes aspectos e a construção e reconstrução de conhecimentos culturais, contribuindo para o desenvolvimento da competência comunicativa, bem como a formação da cidadania dos nossos alunos.

\section{A formação inicial de Letras- Inglês e a extensão: alguns aspectos teóricos}

Segundo (CORTELLA, M, 2006) é inerente à natureza humana não nascermos sabendo tudo nem prontos. Afinal, qual seria nossa determinação para enfrentarmos o novo, se tudo já soubéssemos? Que chance teríamos frente às nossas próprias criações, as máquinas, se não mantivéssemos uma das poucas superioridades da condição humana: o saber agir perante o novo? E enquanto professores em formação inicial, se tudo já soubéssemos e fôssemos prontos, o que motivaria nossa atuação dentro e fora de sala de aula? Perguntar-se-ia: afinal, se tudo já sei ou se tudo já tenho prescrito para o meu fazer, o que sou afinal, o que posso ou preciso ainda aprender?

Para tentar discutir essas questões, referimo-nos primeiramente ao período em que, na formação profissional docente, predominava-se uma ótica conteudista, a partir da qual era esperado dos futuros professores domínio amplo dos conhecimentos culturais e cognitivos em detrimento do saber didático-pedagógico. Período ainda atual, infelizmente, no qual busca-se dissociar o indissociável: o como e o que ensinar. (SAVIANI, 2009 apud GUEDES-PINTO, 2016). Concordamos que essa dissociação é problemática e acreditamos que, a partir de uma formação em que o corpo discente tenha a possibilidade de maior vivência prática, os conteúdos apresentados na academia poderão ser melhor relacionados à realidade profissional. Afinal, nosso campo de atuação é, entre outros, a sala de aula. Acreditamos não haver uma apropriação coerente dos aspectos didático-pedagógicos que regem este trabalho sem a prática profissional.

Uma abordagem teórica que nos permite entender como os saberes de ordem teórica precisam aparecer de forma articulada com os saberes de ordem didático-pedagógica na formação inicial do professor, é a que compreende o ensino como trabalho (MACHADO, 2012; MEDRADO, 2012; MARTINY, 2011). As pesquisas nessa área discorrem acerca do agir docente como atividade dirigida (CLOT, 2009) e rebatem as representações do professor como mero executor de um trabalho prescrito, no qual não há autonomia, criatividade ou contextualização do agir profissional. Na verdade, acreditam que o gênero da atividade docente deve nos permitir quebrar as correntes que nos amarram aos manuais prescritivos, sem comprometer a criatividade, nem nossa capacidade de superar limites. A partir desta perspectiva, acredita-se que o aluno tornar-se-á professor ao avaliar-se a partir de suas dúvidas e desafios durante o percurso e refletir criticamente sobre sua prática, logo compreendendo como uma determinada atividade pode ser redirecionada ou melhorada (MEDRADO, 2012).

Destarte, ao se perguntar o que posso ou preciso ainda aprender, o professor, à luz desta perspectiva, perceberá que é a partir do (re)fazer e da reflexão sobre o seu agir docente 
que sempre aprenderá. (MEDRADO, 2012). No processo do tornar-se professor, processo permanente e em constante transformação, tal qual o nosso vir-a-ser humano, perceberá que, ao se empoderar dos princípios básicos que regem a docência, precisa e deve se libertar do meio comum, para desafiar e transformar sua atividade e os instrumentos que faz uso diante do novo, inesperado, aquilo que não se encontra nos livros e nos faz aprender e chegarmos mais próximos do ser professor (MARTINY, 2011)

Como, então, a extensão pode contribuir para a formação docente à luz de uma abordagem do ensino como trabalho e na qual se busca desenvolver a indissociável dupla forma e conteúdo? A princípio, compreendemos que o fato de o professor em formação assumir o papel docente em uma etapa tão inicial amplia a articulação do que é aprendido em sala e a prática. Não obstante, a presença da coordenadora em sala, guiando os professores e apresentando os princípios do agir docente e ao mesmo permitindo a criatividade na construção dos planos de aula, bem como na resolução das dificuldades enfrentadas no momento real da atividade, pode capacitá-los e aproximá-los das formas de agir típicas do gênero profissional docente. Além disso, os diários reflexivos escritos acerca da prática em sala de aula pelos professores, avaliados e comentados pela professora coordenadora, permitem pensar criticamente sobre como os professores representam os elementos do agir docente, e como os desafios são enfrentados, considerando o real da atividade (CLOT e FAÏTA, 2000 apud MEDRADO, 2012), assim como avaliar de que maneira os professores confrontam seus medos, dúvidas e dificuldades.

\section{A formação inicial de Letras- Francês e a extensão: alguns aspectos teóricos}

O projeto de extensão "Língua e cultura francesa para a comunidade acadêmica e externa" objetivou promover o ensino de Francês e possibilitar uma ampliação do conhecimento de mundo dos alunos, defendendo a diversidade linguística e cultural, além de oferecer ao aluno de Letras Francês a oportunidade de planejar e ministrar aulas complementando sua formação. Neste âmbito, a extensão pode trazer contribuições para o desenvolvimento no processo de formação na graduação, permitindo ao professor ir além da teoria e dos estágios supervisionados do curso, possibilitando autonomia e aliando, de fato, a teoria, a pesquisa e a prática docente em um contexto real de ensino, construindo uma ponte entre a universidade e a sociedade.

Durante uma experiência dessa natureza, percebemos, por exemplo, que o plano de aula pode ser percebido em sua real utilidade pelo professor em formação, ou seja, esse professor identifica de que maneira o plano "facilita o enriquecimento profissional, por ser uma atividade que é motivo de reflexão sobre a prática e um esquema-guia flexível para uma ação consciente dos professores/as" (SACRISTÁN, 2000, p.278) . Corroborando esse pensamento, Lousada e Barricelli (2011, p. 229) afirmam que

É justamente a necessidade de ter uma classe "que funcione" que faz com que os professores, no exercício de seu trabalho, partam das prescrições, elaboradas de maneira geral, para todos, mas adaptem-nas a seu contexto particular de ensino. 
Com a prática extensionista, o professor em formação se depara com dificuldades e imprevistos e o plano de aula se torna essencial para lhe dar mais segurança com a sequência das aulas. Como o plano é flexível, o professor também pode se guiar pelo "bom senso" e fazer adaptações à realidade mutante e imprevisível das aulas (SACRISTÁN, 2000).

Através das vivências em sala de aula e do planejamento de aulas, o professor em formação pode perceber como a reflexão sobre a prática lhe ajuda a enfrentar as dificuldades e situações futuras, e ir se tornando um professor ainda mais reflexivo, pois,

\begin{abstract}
Diante de um contexto educativo e social mutável e complexo, o docente deve tornar-se um prático reflexivo, capaz de adaptar-se a todas as situações de ensino pela análise das suas próprias práticas e de seus resultados. Deve refletir sobre a questão do sentido das ações que efetua, interrogar-se sobre suas próprias concepções, sobre o que faz e porque o faz. Por essa capacidade de "autoanalisar-se", ele pode então "identificar seus sucessos e insucessos" e assim ajustar as suas ações (MAROY, 2008, p.72).
\end{abstract}

No projeto de extensão "Língua e cultura francesa para a comunidade acadêmica e externa", as aulas ministradas também deram ênfase à perspectiva intercultural, o que pode ter contribuído para os professores participantes desenvolverem o que se conhece por competência cultural. Para Legendre (1993), a competência cultural é indissociável da competência comunicativa. Comunicar-se com o outro é conseguir perceber culturalmente seu parceiro linguístico na troca conversacional. Para Denis (2000), a aula de língua constitui um momento privilegiado que permite ao aprendiz descobrir outras percepções e definições da realidade, outros valores, outros modos de vida. Assim, o ensino de língua estrangeira vai além do ensino de formas linguísticas, trata-se do ensino de nova(s) cultura(s), de hábitos, ampliando o conhecimento de mundo do aluno e criando uma cultura de respeito à diversidade e a consequente aceitação do outro.

\title{
5 Saberes construídos a partir da atuação na extensão: Um olhar sobre a experiência de Inglês.
}

Acredito que entre os tantos resultados obtidos por este projeto, a compreensão da teoria do letramento crítico e o ensino específico e instrumental da língua inglesa voltada para capacitação profissional, assim como desenvolvimento social e cidadão dos participantes do projeto e, inquestionavelmente, um verdadeiro aprendizado que este bolsista poderá levar consigo para sua vida acadêmica. (Relatório final, Professor em formação, PROBEX Letras Inglês, dezembro 2015).

A passagem acima, escrita por um dos bolsistas participantes do projeto de extensão voltado para o ensino da língua Inglesa, resume alguns dos principais aprendizados dessa experiência. Entre os conhecimentos essenciais construídos durante essa prática, a utilização pedagógica dos multiletramentos, em especial, do letramento crítico e dos letramentos multissemióticos (ROJO, 2009), o ensino para fins específicos (HUTCHINSON \& WATERS, 1987) e a prática de ensino situada (MEDRADO, 2012) foram peças-chave para o desenvolvimento desse professor em sua formação inicial de língua estrangeira. 
Quanto ao Inglês para fins específicos (doravante IFE), aprendemos que o ensino da língua Inglesa é mais pontual, objetivo e busca capacitar o sujeito a se comunicar brevemente, uma vez inserido em um determinado contexto. De acordo com Vilaça (2010 p.5), esta abordagem consiste em "um ensino baseado em necessidades reais (ou previstas) de aprendizagem e comunicação em língua Inglesa. Assim, o professor em formação pode aprender que o ensino da língua estrangeira deve compreender as necessidades do alunado, não precisando ter todas as habilidades linguísticas desenvolvidas impreterivelmente. O processo ensino-aprendizagem pode ser direcionado para fins específicos. No caso do projeto de extensão em questão, o direcionamento se deu para o contexto do turismo e da hotelaria.

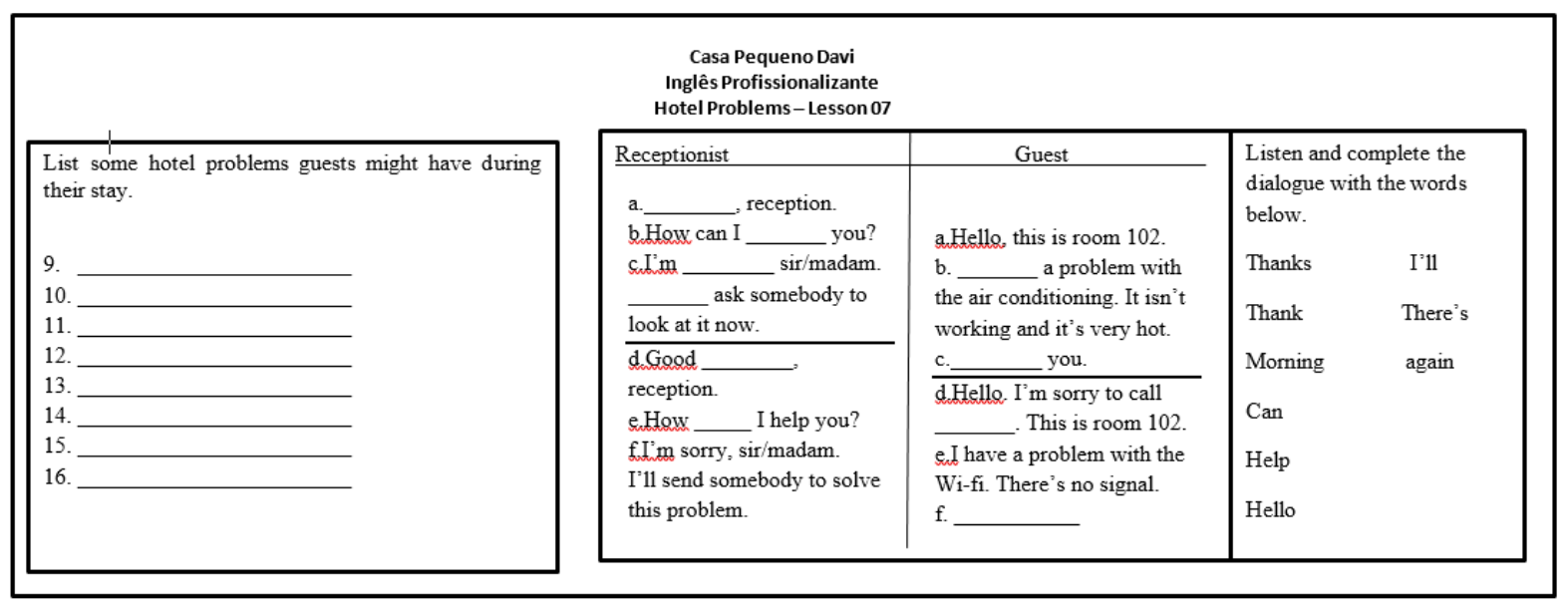

Atividade para IFE. Hotel Problems

Esta imagem exemplifica uma das atividades desenvolvidas com essa abordagem de ensino. É um texto pedagógico, com o qual buscou-se uma prática de língua mais próxima possível da realidade que poderiam encontrar ao precisarem solucionar algum problema enquanto recepcionistas de um hotel. Apoiados pela teoria de Hutchinson e Waters (1987), ao desenvolver este plano, foram enfatizados os três fundamentos do IFE: a necessidade real dos alunos, ou seja, o que precisavam aprender para se inserir no mercado de trabalho do turismo. Ao mesmo tempo, cientes das lacunas de aprendizagem destes alunos, procurou-se abordar outras estruturas gramaticais nesta prática, como o verbo modal can para possibilidade, uma vez que seu uso poderia ser resumido apenas ao sentido de habilidade. Conforme mencionamos, todos os participantes do projeto de extensão já haviam terminado ou estavam com o curso profissionalizante de hotelaria e turismo em andamento. Ou seja, seus anseios pelo aprendizado de algo relevante para seu futuro profissional também foram contemplados.

A partir de atividades como essa e as demais desenvolvidas ao longo do projeto, acreditamos que os objetivos do IFE puderam ser alcançados. Entre as dificuldades para sua implementação, destacam-se o diagnóstico das lacunas de aprendizagem dos sujeitos, como contemplar os interesses de todos, bem como se aproximar ao máximo da língua real utilizada nos contextos abordados. Apesar delas, avaliou-se que se fomentou a formação de sujeitos autônomos, que podem se engajar em um processo de ampliação contínua de saberes, mesmo depois de ter concluído o curso de extensão.

O letramento crítico, por sua vez, compartilha do mesmo objetivo que o IFE, ou seja, formar sujeitos engajados em ampliar seus conhecimentos. Todavia, este conceito expande tanto as noções de língua quanto de sujeito. Língua, aqui, transpõe o mero aspecto instrumental ou profissionalizante. À luz da teoria do letramento, língua é vista como discurso, dinâmico, transformador e construtor de sentidos (JORDÃO, 2012). Ela assume também um caráter 
social, uma vez que há agentes e mediadores em seu uso, que, por sua vez, não ocorre em um vácuo social. (ROJO, 2009). Ao trabalharmos a língua sob este aspecto, buscamos formar cidadãos, conscientes dos múltiplos discursos que os circundam, empoderando-os a agir diante desigualdades ou opressão. Reconhecemo-nos como seres sociais, históricos, pensantes, comunicativos, transformativos e criativos (FREIRE, 1998 apud JORDAO, 2012), aptos a provocar mudanças no mundo, sejam elas pessoais ou para suas comunidades.

[...] A partir dos encontros e discussões acerca do desempenho dos educandos, ratificamos o quanto as discussões acerca de temas abrangentes, o ensino da língua e o enfoque na cidadania possibilitaram (des)construções de pontos de vista existentes entre eles (Relatório final, Professor em formação, PROBEX Letras Inglês, Dezembro 2015).

Como salientado pelo professor no trecho acima, a língua Inglesa durante o projeto foi utilizada para a (des) construção de pontos de vistas existentes entre os participantes. Ao longo da segunda etapa da aula, era proposto a leitura de um breve texto sobre alguma vivência do cotidiano daqueles sujeitos que demandasse o seu posicionamento crítico, sua opinião sobre o tema. Por se tratar de sujeitos advindos de uma comunidade carente e participantes da Casa Pequeno Davi, consideramos válido o debate sobre conteúdos transversais propostos pelos PCNs, como o consumismo, o meio ambiente, igualdade racial e respeito, pois objetivávamos a conscientização sobre seus direitos e deveres enquanto cidadãos.

[...]discussão sobre temas como a exploração sexual, o consumismo, a consciência ambiental, a tolerância para com o diferente possibilitou a inserção dos jovens participantes na sociedade como seres engajados, conscientes de seu papel no contexto inserido, críticos e capazes de se posicionarem frente a situações em que encontrarem a si ou na sua comunidade em situações de vulnerabilidade (Relatório final, Professor em formação, PROBEX Letras Inglês, Dezembro 2015).

A abordagem destes temas era feita a partir de múltiplos gêneros textuais presentes no contexto social dos participantes. Textos de blogs, propagandas, flyers, campanhas de conscientização, vídeos, infográficos e imagens. Sim, chamamos esses gêneros de texto por nos ampararmos no conceito de letramentos multissemióticos (ROJO, 2009). Uma vez que os textos contemporâneos estão em forma de imagens, músicas e outras semioses além da escrita e com os avanços das TICs (tecnologias de informação e comunicação), o espectro de capacidade de leitura deve também englobar as cores presentes no texto, as imagens estáticas ou em movimento, o design escolhido, entre outros aspectos.

[...]perceber novas perspectivas e maneiras de abordar temas e conteúdo de maneira mais crítica e construtiva....a visão deste bolsista acerca do prisma do ensino da língua inglesa para falantes de outro idioma foi ampliada, ao ponto de descontruir verdades absolutas anteriores a esta experiência (Relatório final, Professor em formação, PROBEX Letras Inglês, Dezembro 2015). 
Por fim, e tomando por base o fragmento anterior, talvez um dos maiores aprendizados vivenciados nesta experiência de extensão, o agir docente sob uma ótica socialmente situada. De acordo com Medrado (2012), o ensino deve se preocupar com o conteúdo a ser apresentado, como será feito, onde e quem são os participantes. Do que adiantaria uma aula impecavelmente planejada, com conteúdo e didático bem organizados se não serve ao público ou ao contexto no qual estão inseridos? Faz-se mister considerar o público, sob caráter histórico, sócio e cultural, considerando-os sujeitos holísticos que trazem consigo conhecimento de mundo prévio, concepções de vida bem definidas pelas experiências árduas que a vida já lhes propiciou.

Não menos importante, a experiência com o projeto de extensão na ONG Casa Pequeno Davi, demonstrou que o ensino deve, acima de tudo, ser utilidade pública e retorno social (OLIVEIRA, M.R; WILSON, U. apud MARTELOTTA, 2008). Independente do contexto que ensinarmos, somos formadores de opiniões, incapazes de assumir um papel absolutamente neutro, pois, como premissa de nosso gênero profissional, temos o compromisso social de formarmos cidadãos.

\section{Saberes construídos a partir da atuação na extensão: Um olhar sobre a experiência de Francês.}

Por meio das vivências durante o projeto de extensão "Língua e cultura francesa para a comunidade acadêmica e externa", foi possível para a professora em formação participante relacionar os saberes teóricos vistos durante o curso de Letras com o campo de atuação profissional, contribuindo assim para a sua formação inicial e para a construção de uma identidade profissional. Com as experiências vivenciadas e as habilidades adquiridas neste projeto, ela se sentiu mais segura para desenvolver atividades diferentes na prática diária. Das dificuldades encontradas foram ganhos novos aprendizados.

No contexto deste projeto, a turma de francês era heterogênea, com idades e grupos sociais distintos, situação esta que gerou desafios na elaboração dos planos de aula, na tentativa de contemplar todos os alunos.

[...] a heterogeneidade que caracteriza a sala de aula é um conceito abrangente. Envolve a diversidade de habilidades cognitivas dos alunos, estilos e ritmos de aprendizagem, fatores socioeconômicos e familiares, influências culturais e étnicas, influências de gênero, valorização da aprendizagem pelo aluno e pela família, confiança em si e desejo de aprender, entre outros aspectos. Essa diversidade constitui a riqueza da sala de aula e as múltiplas possibilidades de interações sociais e mediações sociais e pedagógicas (MAINARDES, 2008, p.130).

Assim, procuramos adaptar o material didático de acordo com a realidade sociocultural do aluno. Por exemplo, foi adotado o livro didático (MOBILE A1 - Didier) como um guia/roteiro para as aulas, porém, muitos dos seus conteúdos fugiam da realidade cotidiana no aluno brasileiro. Nesses casos, criou-se materiais a partir de documentos autênticos e adaptou-se o material do livro para uma prática pedagógica mais eficaz. Em uma das lições do livro intitulada "A cultura está no prato" (La culture est dans l'assiette), exploraram-se as imagens que ilustravam duas famílias (uma francesa e uma chinesa) e os seus hábitos alimentares. Assim, os questionamentos foram trazidos para a realidade brasileira, debatendose sobre a cultura gastronômica no Brasil. Foi uma aula interessante, na qual os alunos 
ganharam voz e se aproximaram do conteúdo estudado, podendo comparar os seus hábitos alimentares com os daquelas outras culturas presentes no método.

A partir desta atuação na extensão, foi possível à professora em formação refletir e constatar que o professor de língua estrangeira não precisa ser um dicionário. Ela teve que aprender a lidar com as situações em que os alunos faziam perguntas para testar seu nível de conhecimento ou simplesmente para tirar uma dúvida de uma expressão específica da cultura francesa. Nestes momentos, a depender da expressão, eram feitas pesquisas e a professora trazia as respostas nas aulas subsequentes e os possíveis usos dessas palavras/expressões. Além disso, foi incentivada a autonomia do aluno em sala de aula, mostrando-lhes a utilidade do dicionário para pesquisas ou mesmo do smartphone, que tem acesso à internet e é uma ótima ferramenta de auxílio ao aprendizado (TIC) quando bem utilizada.

Na aula autônoma, o professor precisa aprender que ele deixa de ser a autoridade máxima, tanto em termos de controle como em termos de conhecimento. Não é mais o dono do saber, que tipicamente só faz as perguntas que ele mesmo sabe responder. $\mathrm{Na}$ aula autônoma, qualquer pergunta pode aparecer e o professor obviamente não tem a obrigação de saber todas as respostas. Seu papel é realmente o de facilitador da aprendizagem, ajudando o aluno a desenvolver sua autoconfiança, a se tornar ainda mais autônomo e ficar menos dependente dele, professor (LEFFA,2003, p. 43).

No início das aulas, sob orientação da professora coordenadora do projeto, foi aplicado um questionário aos alunos, e através deste questionário constatamos que os alunos apresentaram objetivos variados quanto à aprendizagem da língua e cultura francesa: enriquecer o currículo acadêmico e profissional, a pesquisa científica, a comunicação e a cultura, além do turismo. Verificamos a partir do questionário que a maioria dos alunos inscritos nunca haviam tido contato com a língua e cultura francesa e, os que já tiveram algum contato, foi pouco, de curta duração ou há muito tempo. Este questionário foi importante para que a professora pudesse conhecer seus alunos, suas expectativas e suas representações acerca da língua e cultura francesas.

A cada aula, um novo planejamento e uma nova reflexão surgiam diante das situações e das experiências vivenciadas, lidando com as dificuldades. Assim, o professor "deve seguir um processo cíclico de investigação na ação: pensar antes de decidir, observar ou registrar o que acontece quando se realiza e aproveitar os resultados e anotações tomadas sobre esse processo seguido para voltar a planejar o momento seguinte e ter em mente como se há de fazer outra vez" (SACRISTÁN,2000, p.276)

No último dia de aula, os alunos responderam um portfólio de auto avaliação visando verificar as competências linguísticas e culturais assimiladas pelos alunos durante o curso. No contexto de ensino de uma língua estrangeira o portfólio pode ser utilizado como parte da avaliação do ensino/aprendizado, produzindo uma visão global desse processo e para o desenvolvimento da competência comunicativa, autonomia, e capacidade de reflexão.

Neste projeto o portfólio foi feito para que houvesse uma auto avaliação de competências, um espaço de reflexão do aluno sobre seu aprendizado e sobre a sua relação com a nova língua e cultura. No portfólio elaborado, os alunos tiveram a oportunidade de auto avaliar as suas quatro habilidades da língua: o ouvir, o falar, o ler e o escrever. Isso permitiu a reflexão sobre o vocabulário e estruturas gramaticais que foram aprendidos. Neste diapasão, o portfólio aplicado permitiu que a professora em formação aprendesse a avaliar as competências que os alunos mais desenvolveram durante o curso e, através de reflexão, repensar as suas práticas positivas e as suas falhas durante este período. Todos esses questionários aplicados serviram 
como base para a elaboração do meu relatório final de estágio, onde pude refletir sobre toda essa vivência durante o projeto de extensão.

A passagem abaixo resume bem a contribuição deste projeto para a formação inicial docente, escrita no relatório final do projeto de extensão de língua francesa:

Os alunos tiveram um contato com a língua estrangeira de forma interativa, ressaltando-se que este projeto teve como meta a comunicação de língua e de cultura francesa. A prática extensionista permitiu confirmar a boa recepção das atividades propostas. A relação com os meus alunos foi excelente, criamos uma relação afetuosa, todos me receberam muito bem e acho que eu pude contribuir para a evolução deles durante este curso. De modo geral, cumpri as minhas metas e esse período foi muito enriquecedor para a estudante de Letras-Francês que sou e futura professora de francês que serei um dia. (Relatório final, Professora em formação, PROBEX Letras Francês, Dezembro 2015).

Também é preciso destacar que na prática extensionista a integração entre o professor-formador e o aluno-professor foi essencial neste projeto, porque foram nas reuniões entre esses participantes do projeto que havia uma troca de saberes e a professora em formação era orientada sobre como agir da melhor maneira em sala de aula. Reconhecemos o orientador como peça essencial no processo formativo, pela troca de experiências realizada e pelas dicas sugeridas.

\section{Considerações finais}

Concluímos esta análise interpretativa dos dados colhidos ao longo das atividades do projeto de extensão com algumas considerações sobre a importância da Extensão no processo de formação inicial do professor de letras estrangeiras. De início, reconhecemos o espaço da extensão como propício para o processo de se fazer professor. A partir da vivência docente, com todos os aspectos que compõem este gênero profissional, como o planejamento, adaptação de materiais e execução de aulas, o professor em formação inicial é encorajado a mobilizar o conhecimento acadêmico em uma perspectiva prática, na qual há a possibilidade de se combinar a forma, ou seja, os aspectos didático-pedagógicos, e o conteúdo, o aparato linguístico que os sujeitos participantes da extensão buscam e necessitam para engajar-se em sociedade através da língua(gem). Além disso, através dos relatos reflexivos, o aprendizado de se fazer professor aconteceu através de uma perspectiva crítica de ensino-aprendizagem, a qual nos retirou da zona de conforto do fazer prescritivo e nos possibilitou criar, desafiar nossos medos e superar as dificuldades e desafios que se materializaram enquanto vivenciávamos o real da atividade.

Através da perspectiva dos múltiplos letramentos e do interculturalismo, tivemos nos concepções de linguagem ampliadas, uma vez que ambas as teorias nos ensinaram que a língua é uma prática social, que (des)constrói sentidos e não pode ser tratada meramente como um código ou um instrumento para profissionalização. Ela é dinâmica, transformadora e jamais descontextualizada, uma vez que não ocorre em um vácuo social. Há agentes e mediadores, seres holísticos e com pontos de vista distintos, buscando aprender a língua estrangeira para agir no mundo e propor mudanças em suas vidas, como também daqueles presentes em seu contexto social. Estas teorias nos ensinaram que a leitura hoje deve ir além dos signos verbais. Com o desenvolvimento das TICs, os signos não-verbais, como o movimento, som, cores e design, presentes em gêneros textuais 
como a música e vídeos estão presentes e devem ser explorados, de forma a educar indivíduos capacitados a lê-los e utilizados em sociedade.

Por fim, aprendemos com os projetos de extensão que o agir docente engloba muito mais que o papel do professor como transmissor de conhecimento, uma vez que o professor não é o único detentor de saberes em sala de aula. O papel social do professor engloba a formação de cidadãos engajados e comprometidos com a justiça social, conscientes de seus deveres, aptos a agir criticamente contra discursos opressores e empoderados para buscar seus direitos em sociedade. Acreditamos, a partir dos saberes construídos na experiência que apresentamos nesse trabalho, que a extensão é um espaço mais que propício para o desenvolvimento profissional de professores que estejam engajados com essa visão politicamente situada e comprometida do trabalho docente e da educação linguística na atualidade.

\section{REFERÊNCIAS BIBLIOGRÁFICAS}


BRASIL. Orientações curriculares para o ensino médio: linguagens, códigos e suas tecnologias. Brasília: MEC, Secretaria da Educação Básica, 2006.

CHIANCA, R.M.S Interagir em língua estrangeira: um assunto sociocultural. Tradução: Elisa Nóbrega; Ingrid Farias Fechine Oliveira; Sandra Helena Gurgel Dantas de Medeiros. In: MOARA, Revista dos Cursos de Pós-Graduação em Letras da UFPA. Belém: Editora Universitária / UFPA, n.11, p. 1-164, jan./jun.,1999, p.65-84, 2006.

CLOT, Yves. A função psicológica do trabalho. Petrópolis, RJ: Vozes, 2006.

DENIS, M. Développer des aptitudes interculturelles em classe de langue. In: Dialogue et cultures. N.44. Disponível em: http://www.europschool.net/francais/rubriques/formation/pdf/interventions_salon/denis.pdf > Acesso em: 20 de outubro de 2016.

GUEDES-PINTO, A. Vozes dos estagiários: articulações entre práticas de letramento e construção de sentidos para a profissão docente. In: KLEIMAN, J. Significados e ressignificações do letramento: desdobramentos de uma perspectiva sociocultural sobre a escrita. Campinas, SP: Mercado de Letras, 2016 pp. 345-366

HUTCHInson, T., \& WATERS, A. English for Specific Purposes: A learning-centered approach. Cambridge: Cambridge University Press, 1987

JORDAO, Clarissa Menezes; FOGACA, Francisco Carlos. Critical literacy in the english language classroom. DELTA, São Paulo , v. 28, n. 1, p. 69-84, 2012 . Available from $<$ http://www.scielo.br/scielo.php?script=sci_arttext\&pid=S0102-

44502012000100004\&lng=en\&nrm=iso>. access on 13 Nov.

2016. http://dx.doi.org/10.1590/S0102-44502012000100004.

LEFFA, V. J. . Quando menos é mais: a autonomia na aprendizagem de línguas. In: Christine Nicolaides; Isabella Mozzillo; Lia Pachalski; Maristela Machado; Vera Fernandes. (Org.). O desenvolvimento da autonomia no ambiente de aprendizagem de línguas estrangeiras. Pelotas: UFPEL, 2003, v. , p. 33-49.

LEGENDRE R. dir. Dictionnaire Actuel de l'Education, $2^{\circ}$ éd., Education 2000, Montréal, Guérin/Paris, Eska, imprimé au Canadá, 1993.

LOUSADA, E. G.; BARRICELLI, E. Análise comparativa de textos que orientam o trabalho educacional: décadas diferentes, mesmas prescrições. In: Eutomia: Revista de Literatura e Linguística, ISSN 1982-6850, 2011, pp. 224-246. Disponível em: <http://www.revistaeutomia.com.br/v2/wpcontent/uploads/2011/12/ELIANE_LOUSADA_ERM ELINDA_BARRICELLI_An\%C3\%A1lise-comparativa-de-textos_p.224-246.pdf.> Acesso em: 20 setembro de 2016.

MAINARDES, J. Escola em ciclos: processos de aprendizagem e intervenções pedagógicas: algumas reflexões. In: FETZNER, A. R. (Org.). Ciclos em revista - v. 4: a aprendizagem em diálogo com as diferenças. Rio de Janeiro: WAK, 2008, p. 118 - 139.

MAROY, C. O modelo do prático reflexivo diante da enquete na Bélgica. In TARDIF, Maurice e LESSARD, Claude (orgs.) O OFÍCIO DE PROFESSOR: História, perspectivas e desafios internacionais. Petrópolis: Vozes, 2008.

MARTINY, Francieli Freudenberger. "Eu não sei dar aula": representações de uma professora iniciante sobre o trabalho docente. In: MEDRADO, B e PÉREZ, M. Leituras do Agir Docente: A 
atividade educacional à luz da perspectiva interacionista sociodiscursiva. Campinas, SP: Pontes Editores, 2011 pp. 157-175.

MEDRADO, B. Tornando-se professor. A compreensão de graduandos em letras sobre a atividade educacional. In: (Org). Projetos e práticas na formação de professores de língua inglesa. João Pessoa: Editora da UPFB, 2012. p.151-169.

OLIVEIRA, M.R; WILSON, U. Línguística e ensino. In MARTELOTTA, M. E. Manual de linguística. 2ed. São Paulo: Contexto, 2015. pp. 235-242

ROJO, Roxane. Letramento(s) - Práticas de letramento em diferentes contextos. In Letramentos Múltiplos, escola e inclusão social. São Paulo: Parábola, 2009 p.95-121.

SACRISTÁN, J. Gimeno; PÉREZ GOMES, A. I. Compreender e transformar o ensino. 4. ed. Porto Alegre: ARTMED, 2000 